
internationales

vol. 36 - $n^{\circ} 4 \mid 2020$

La citoyenneté au temps de l'« intégration civique » : regards croisés France/Canada

\title{
Parrot Karine, Carte Blanche : l'État contre les étrangers
}

Marie Françoise Valette

\section{(2) OpenEdition}

Journals

Édition électronique

URL : https://journals.openedition.org/remi/17740

DOI : $10.4000 /$ remi. 17740

ISSN : $1777-5418$

Éditeur

Université de Poitiers

Édition imprimée

Date de publication : 31 décembre 2020

Pagination : 201-203

ISBN : 979-10-90426-68-9

ISSN : 0765-0752

Référence électronique

Marie Françoise Valette, "Parrot Karine, Carte Blanche : l'État contre les étrangers », Revue européenne des migrations internationales [En ligne], vol. 36 - n4 | 2020, mis en ligne le 31 décembre 2020, consulté le 27 avril 2022. URL : http://journals.openedition.org/remi/17740 ; DOI : https://doi.org/10.4000/remi. 17740

Ce document a été généré automatiquement le 27 avril 2022.

(c) Université de Poitiers 


\title{
Parrot Karine, Carte Blanche : l'État contre les étrangers
}

\author{
Marie Françoise Valette
}

\section{RÉFÉRENCE}

Parrot Karine (2019) Carte Blanche : l'État contre les étrangers. - Paris : La fabrique éditions. - 328 p., ISBN : 978-2-358721790

1 Les ultimes phrases de l'ouvrage de Karine Parrot reflètent infiniment mieux les caractéristiques de son analyse que ne le ferait le rappel des titres et fonctions académiques de l'auteure. Loin de livrer une publication austère visant un public limité aux juristes spécialisés en droit des étrangers, la professeure de droit, membre du GISTI, s'adresse avec talent et passion à tous ceux que le sort réservé aux étrangers en France révolte. Le style clair et efficace rend la lecture d'autant plus facile que les informations mêlent une analyse des normes, de la jurisprudence et surtout un grand nombre d'exemples de la pratique, donnant une dimension très humaine à des situations dramatiques. Ce qui aurait pu n'être qu'anecdote nourrie par une gouvernance absurde et cynique, devient objet de luttes des militants du GISTI auxquelles cette Carte blanche doit beaucoup, tant dans la forme que dans le fond. En effet, en mettant sa rigueur académique au service de plaidoiries sans concession, Karine Parrot témoigne non pas seulement des conséquences de violations du droit, mais surtout de la noirceur d'un droit qu'elle montre au service d'objectifs infects. C'est ainsi, qu'évoquant les demandes d'asile, elle souligne que « l'arbitraire du tri est habillé par le droit ». Cet angle d'approche confère indéniablement une originalité à l'ouvrage, et justifie le choix d'une maison d'édition politiquement engagée, plutôt qu'un des éditeurs juridiques traditionnels. Il contribue à l'ouverture à lectorat plus large.

2 Si la sociologue Liora Israël proposait, en 2009, L'arme du droit dans la perspective d'outil de contestation, cette arme apparaît ici exclusivement au service de dispositifs répressifs contre des étrangers vulnérables. Autant dire que ce livre est sombre de la 
première à la dernière page. L'état de droit ne serait-il que mal en point, l'administration en de mauvaises mains? Inutile d'espérer des lendemains meilleurs au détour d'élections législatives, avec l'avènement d'un nouveau·elle présidente de la République ou par l'instauration d'une VIe République martèle Karine Parrot. Le mal serait nettement plus profond et seul un changement radical de modèle passant par l'abandon d'une société interétatique pourrait favoriser un traitement humain de tous les étrangers.

3 Le moins que l'on puisse dire est que la richesse de la documentation de cet essai est proportionnelle à la vivacité du ton de son auteure. On pourra regretter, sans pour autant en faire grief à cette dernière, le choix retenu par l'éditeur de la relégation des notes en fin d'ouvrage. Celles-ci contribuent largement à l'intérêt de ce dernier. Or leur consultation est d'autant plus malaisée que leur numérotation n'est pas continue, mais redémarre à chaque chapitre. Et elles occupent soixante-neuf pages !

4 À l'inverse, le lecteur appréciera la clarté de la construction du livre autour de quatre chapitres aux titres brefs et très significatifs : I. La nationalité, privilège de naissance, II. Barrières juridiques, frontières assassines, III. La lutte contre l'immigration légale : contrôler, trier, précariser et IV. La lutte contre l'immigration illégale : contrôler, enfermer, faire disparaître.

5 L'ouvrage ayant été publié avant la pandémie de COVID 19, le lecteur pourra cependant remarquer que toutes les conséquences de cette situation sanitaire sur les migrants les plus pauvres apparaissent comme inscrites dans la continuité des situations décrites. En effet, Karine Parrot témoigne du fait que l'étranger malmené par l'État est caractérisé, non pas seulement par sa nationalité, mais aussi par sa pauvreté. C'est en quelque sorte une double altérité qui le conduit à une profonde marginalisation.

6 L'invention de la nationalité, suivie près d'un siècle plus tard par celle d'une « immigration » irrégulière apparaissent comme les deux étapes fondamentales d'une création de normes au service d'un État intrinsèquement violent. L'objectif de " gestion des flux migratoires » fixé par la coopération européenne apparaît aussi absurde que complémentaire des outils précédemment inventés par la France. Chacune de ces affirmations est minutieusement exposée et démontrée à l'aide de nombreux exemples, donnant incontestablement une grande valeur à ce travail, tant pour les militants associatifs, que pour les juristes. Chacun comprendra que ni les dimensions ni l'objet de l'analyse ne permettent la multiplication de comparaisons. Cependant, certains lecteurs pourront en regretter l'absence totale, aussi bien dans une dimension historique, que géographique. C'est par exemple le cas concernant le placement en rétention d'enfants, accompagnés ou non de leurs parents. Si la politique des États-Unis de Donald Trump sur le sujet est désormais bien connue, il serait intéressant de connaître d'autres pratiques étatiques, notamment pour savoir si certains États ont développé des solutions alternatives, telles que la Cour européenne des droits de l'Homme a pu le suggérer dans ses arrêts condamnant la France ${ }^{1}$. Sur ce sujet, accompagner le rappel de la position de la Cour de cassation en soulignant les conclusions de l'avocat général Pierre Chevalier, certes non suivies, aurait apporté une petite lueur positive ${ }^{2}$.

7 Cet ouvrage nourrit l'envie d'en connaitre plus sur les causes profondes de cette situation, mais aussi sur les possibilités d'y mettre fin. En effet, aussi magistral soit-il sur l'état actuel du droit français et de sa pratique, il reste moins convaincant quant aux origines des objectifs recherchés par l'État. À supposer que le capitalisme soit 
responsable de tout, le lecteur aimera connaître le traitement des étrangers sous d'autres régimes, d'où la nécessité d'une suite offrant une dimension comparative! Enfin les communautés politiques à plus petite échelle sont présentées comme seules sources d'espoirs. Mais leur généralisation n'est-elle pas pure utopie? On en conviendra aisément, les possibles de ces modes d'organisation sociétaux relèvent d'un champ de recherche bien différent.

\section{NOTES}

1. Cour.eur.dr.h, Popov contre France, 19 janvier 2012, § 119.

2. Ces conclusions ont été publiées à l'A.J.D. A, 2010, p. 435.

\section{AUTEURS}

\section{MARIE FRANÇOISE VALETTE}

Maître de conférences en droit public, Université de Poitiers/MIGRINTER 